\title{
Therapeutic possibilities of the class II/1 abnormality in early temporary and mixed dentition
}

\author{
Posibilităţi terapeutice ale anomaliei de clasa II/1 în dentaţia temporară şi \\ mixtă incipientă
}

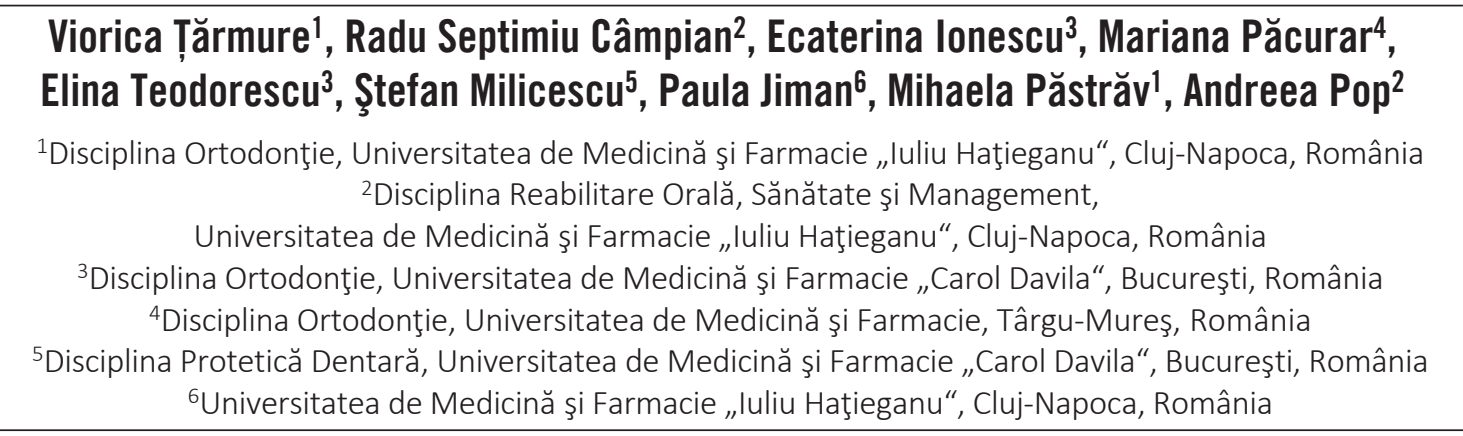

\begin{abstract}
Objectives. The establishment of the frequency of class II/1 in the requests of treatment in Clinica de Ortodontie Cluj between the years 2014 and 2017, the clinical and telegraphic evaluation of the cases with class II/1 and the therapeutically approach of class II/1 cases.

Material and method. The study was made on a lot of 1,830 patients, which came to two of the clinics' offices.

Results and discussions. The incidence of class II/1 at two of the Clinics offices between the years 2014 and 2017 was $47 \%$ (861 cases) of the total of studied cases. The repartition regarding the sexes showed a predominance of $69 \%$ at girls (592 cases).

Conclusions. The frequency of class II/1 anomalies was high in treatment requests, $47 \%$. Treatment in temporary and mixed dentition was done mainly with the functional appliances. The evolution of cases was favorable generally, demonstrated by clinical and cephalometric modifications. There were some limitations in the treatment with functional and removable appliances, the finishing stages will be done with fixed appliances.
\end{abstract}

Keywords: class II/1, therapeutical approach, modern therapy, classic therapy

\section{REZUMAT}

Obiective. Stabilirea frecvenţei anomaliilor de clasa II/1 în solicitările de tratament în Clinica de Ortodonţie din Cluj în perioada 2014-2017, evaluarea clinică şi teleradiografică a cazurilor cu anomalii de clasa II/1, abordarea terapeutică a cazurilor de clasa II/1 în funcţie de vârstă.

Material şi metodă. Studiul a fost efectuat pe un lot de 1.830 de pacienţi, care s-au prezentat la două dintre cabinetele Clinicii.

Rezultate şi discuții. Incidența anomaliilor de clasa II/1 la două dintre cabinetele clinicii în perioada 20142017 a fost de $47 \%$ (861 de cazuri) din totalul cazurilor studiate. Repartiţia în funcţie de sex a arătat o predominenţă a anomaliei la fete de $69 \%$ (592 de cazuri).

Concluzii. Frecvenţa anomaliilor de clasa II/1 a fost ridicată în solicitările de tratament 47\%, tratamentul în dentaţia temporară şi mixtă s-a realizat în mare majoritate a cazurilor cu aparate funcţionale. Evoluţia cazurilor a fost în general favorabilă, demonstrate de modificările clinice şi cefalometrice, existând însă anumite limite în terapia cu aparate funcţionale şi mobilizabile, finisarea urmând a fi continuată cu aparate fixe.

Cuvinte cheie: clasa II/1, abordare terapeutică, terapie modernă, terapie clasică 


\section{INTRODUCERE}

Sindromul ocluziei distalizate, clasa II/1 Angle, este o tulburare de poziție a mandibulei, în sens sagital, în raport cu maxilarul şi restul masivului facial. Este determinată de dezechilibrul dintre muşchii propulsori, care sunt în hipofuncție, şi muşchii retropulsori, care sunt în hiperfuncție (retrognație mandibulară funcțională), sau de un deficit de dezvoltare a mandibulei, cu sau fără afectarea formei sale (retrognație mandibulară anatomică) (1-7).

Pentru a aprecia incidența acestei anomalii de clasa II/1, am efectuat un studiu statistic pe un lot de 1.830 de pacienți care s-au prezentat pentru tratament ortodontic la Clinica de Ortodonție Cluj în perioada 2014-2017. Prelucrarea datelor statistice a fost făcută în funcție de vârsta pacientului, de sex şi de tipul de anomalii asociate.

În funcție de vârsta pacientului, de felul dentației şi gravitatea anomaliei, abordarea terapeutică a fost diferită atât cu aparate funcționale şi mobilizabile de tip clasic, cât şi cu terapie fixă modernă.

\section{MATERIAL ŞI METODĂ}

Studiul a fost efectuat pe un lot de 1.830 de pacienți, care s-au prezentat la două dintre cabinetele Clinicii de Ortodonție din cadrul UMF „Iuliu Hațieganu“, Cluj-Napoca. Diagnosticul de anomalie de clasa II/1 s-a bazat pe următoarele criterii:

\section{Diagnosticul morfologic:}

- facies caracteristic;

- profil convex;

- rapoarte de distalizare la canini şi molari;

- test de propulsie a mandibulei pozitiv;

- relaţii scheletice de clasa a II-a.

\section{Diagnostic etiologic:}

- lipsa alimentației naturale;

- respirație orală;

- poziția joasă şi posterioară a limbii;

- parafuncții şi obiceiuri vicioase;

- contacte premature.

Planul terapeutic a fost stabilit în funcție de:

- vârstă;

- gravitatea anomaliei;

- anomaliile asociate;

- prezența sau nu a parafuncțiilor sau a obiceiurilor vicioase;

- colaborarea cu pacientul;
- aparatele utilizate;

- evoluția cazurilor.

\section{REZULTATE ŞI DISCUŢII}

Incidența anomaliilor de clasa II/1 la două dintre cabinetele Clinicii de Ortodonție în perioada 20142017 a fost de $47 \%$ (861 de cazuri) din totalul cazurilor studiate (Fig. 1).

La lotul studiat, grupa de vârsta 9-12 ani a fost cea mai afectată $41 \%$ (352 de cazuri) (Fig. 2). Repartiția în funcție de sex a arătat o predominență a anomaliei la fete de 69\% (592 de cazuri) (Fig. 3).

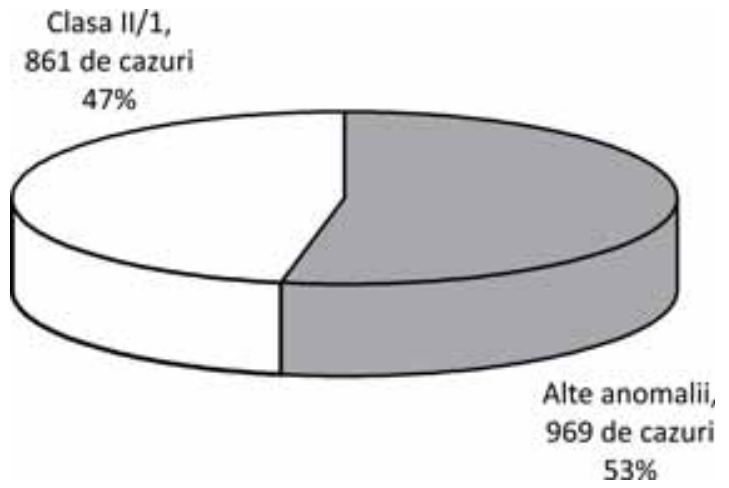

FIGURA 1. Incidența anomaliilor de clasa II/1 din totalul cazurilor studiate



FIGURA 2. Repartiția în funcție de vârstă

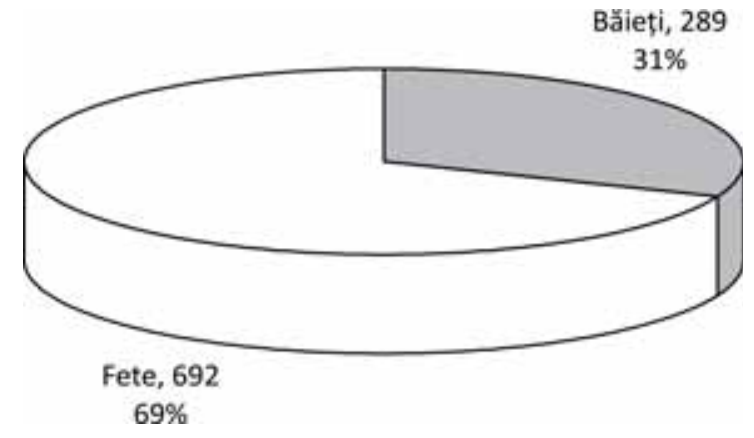

FIGURA 3. Repartiția în funcție de sex 




35

FIGURA 4. Repartiția în funcție de aparatele utilizate

În dentația temporară, aparatele folosite au fost scuturile vestibulare standard şi cele confecționate în laborator.

Pentru ilustrare vom prezenta câteva cazuri.

\section{Caz 1 - P.M. 5 ani (Fig. 5, 6, 7, 8)}

Pacienta prezenta respirație orală, cu buze uscate, fisurate şi test Gudin pozitiv.

Pentru decondiţionarea respirației orale şi antrenament muscular, s-a utilizat plăcuța vestibulară.



FIGURA 5. Aspect din normă frontală

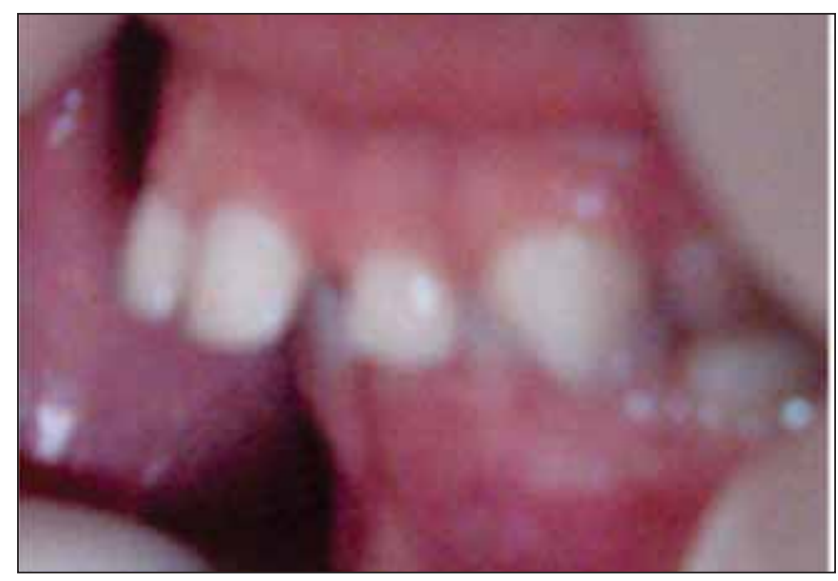

FIGURA 6. Aspect endobucal treaptă sagitală apreciabilă

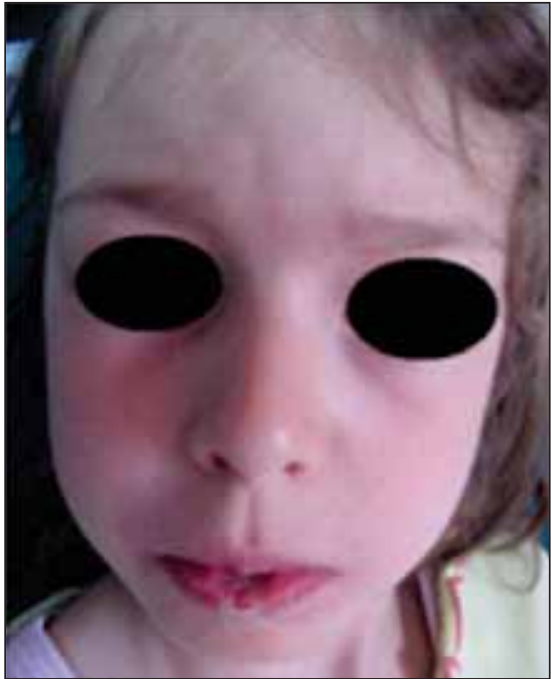

FIGURA 7. Plăcuță vestibulară standard (aspect exobucal al pacientei purtând plăcuța vestibulară)

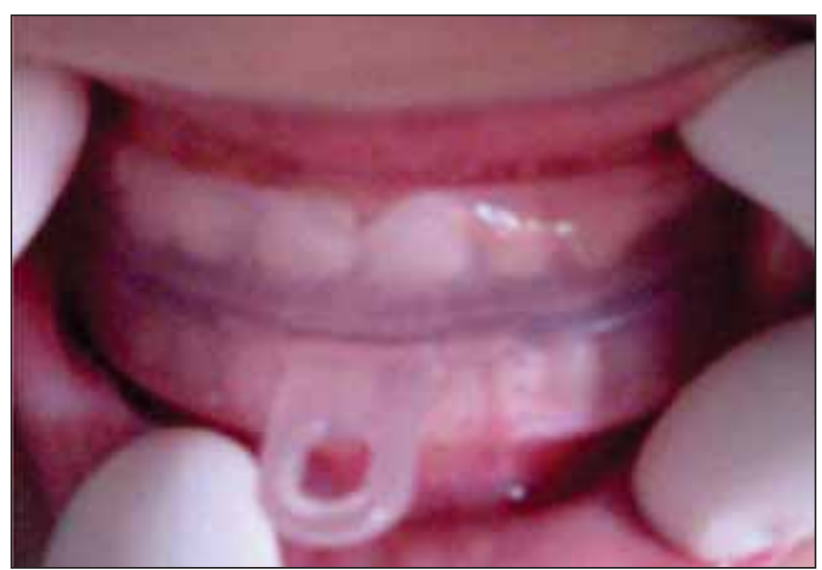

FIGURA 8. Placuță vestibulara standard (aspect endobucal)

\section{Caz 2 - M.I. 10 ani}

Diagnostic: clasa II/1 (retrognaţie mandibulară funcțională, maxilar îngust cu protruzie şi inghesuire, 13 cu spațiul de erupție redus, ocluzie adâncă în acoperiş) (Fig. 9, 10, 11).

Tratamentul s-a realizat cu un aparat funcțional tip Twin Block (Fig. 12, 13).

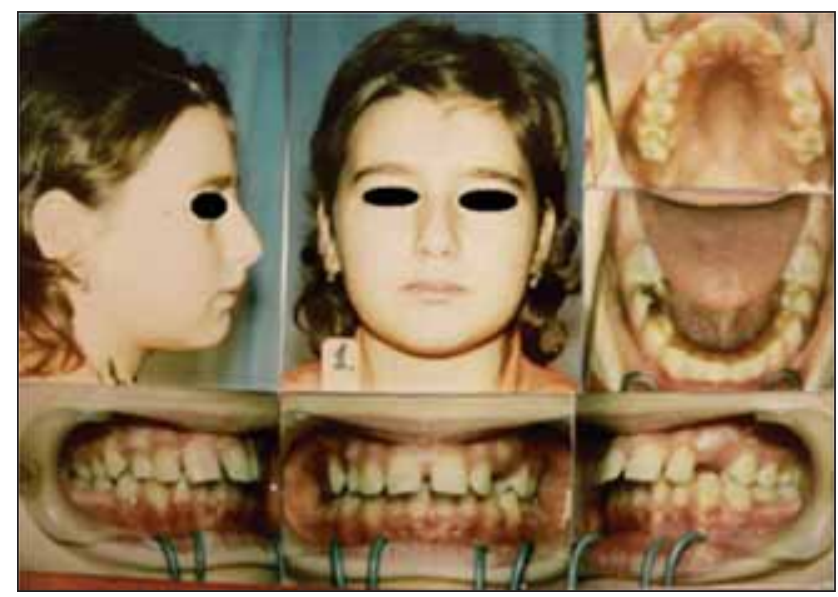

FIGURA 9. Aspect clinic exo şi endobucal 


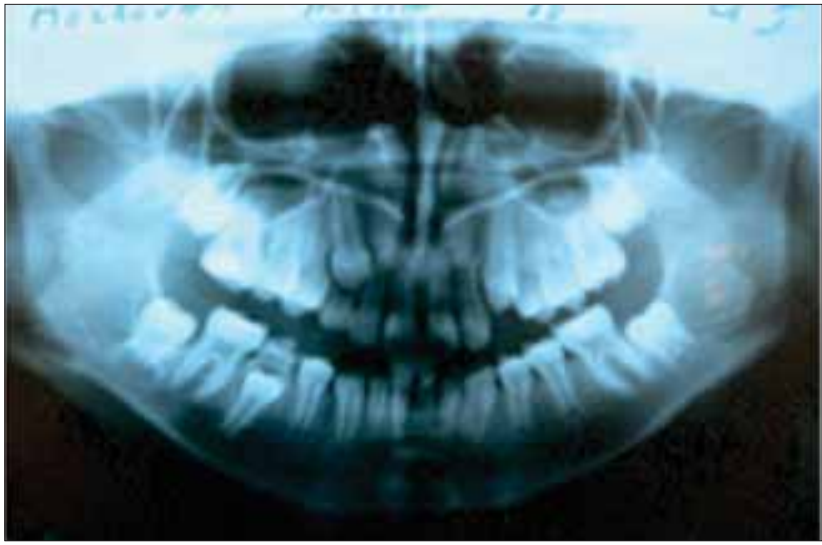

FIGURA 10. OPT inițial

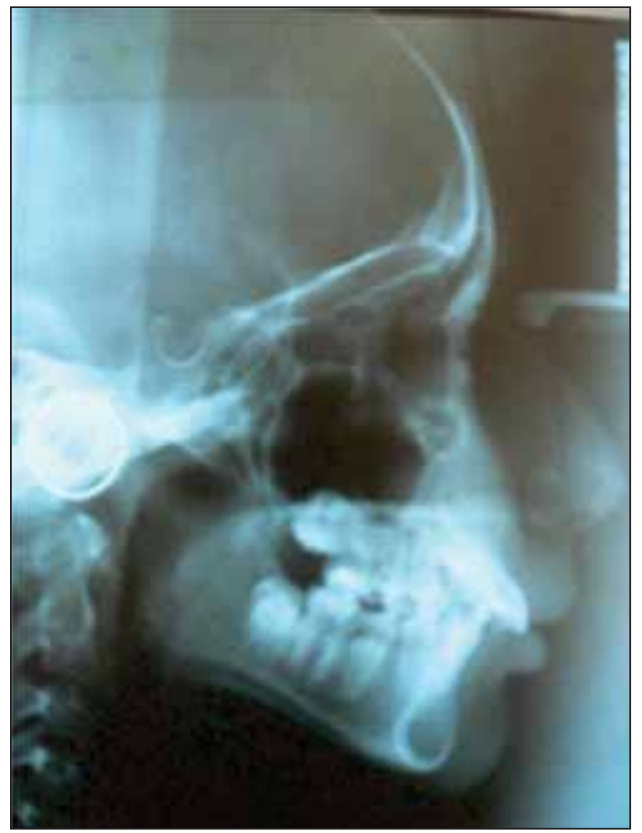

FIGURA 11. Teleradiografia de profil inițială

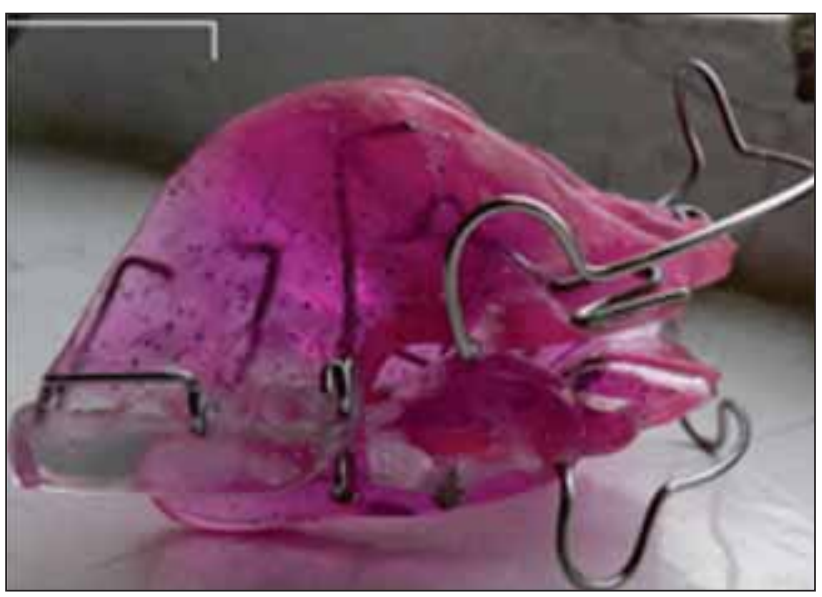

FIGURA 12. Twin Block, aspect exobucal

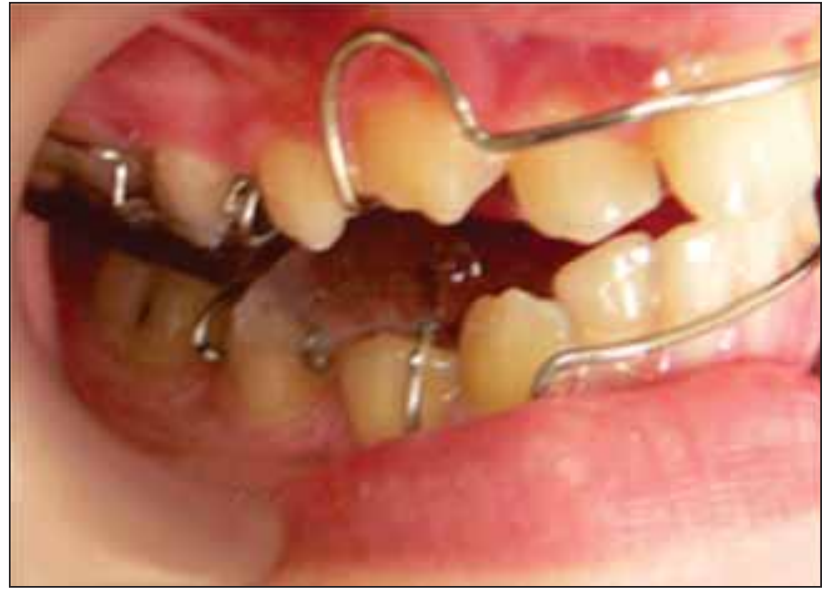

FIGURA 13. Twin Block, aspect endobucal

Etapă intermediară: 14 luni de la aplicarea aparatului (Fig. 14, 15, 16)

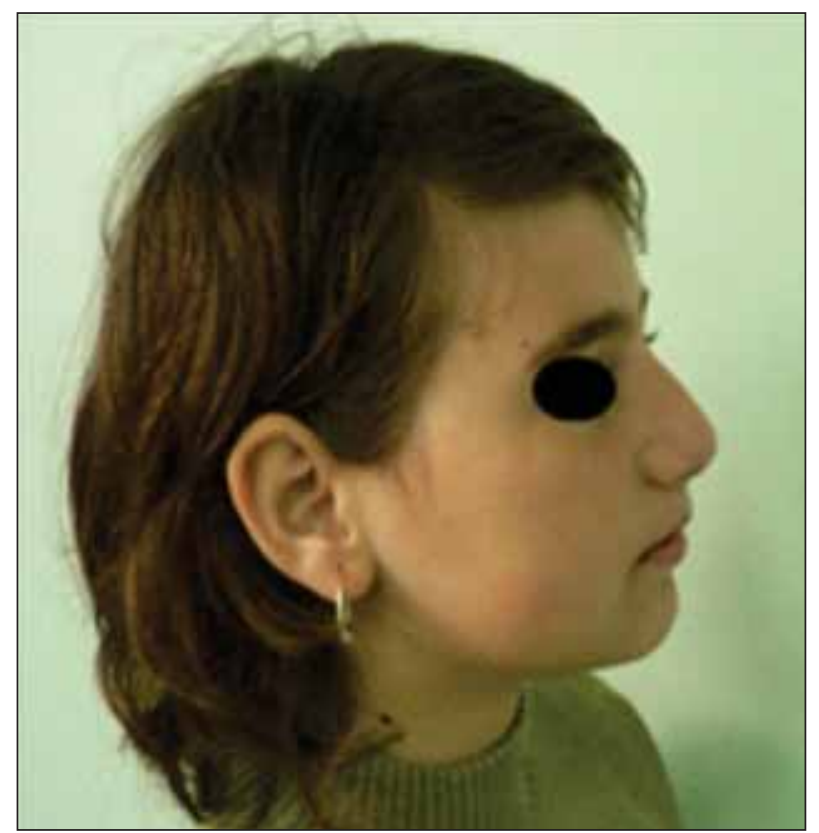

FIGURA 14. Aspect endobucal din normă laterală

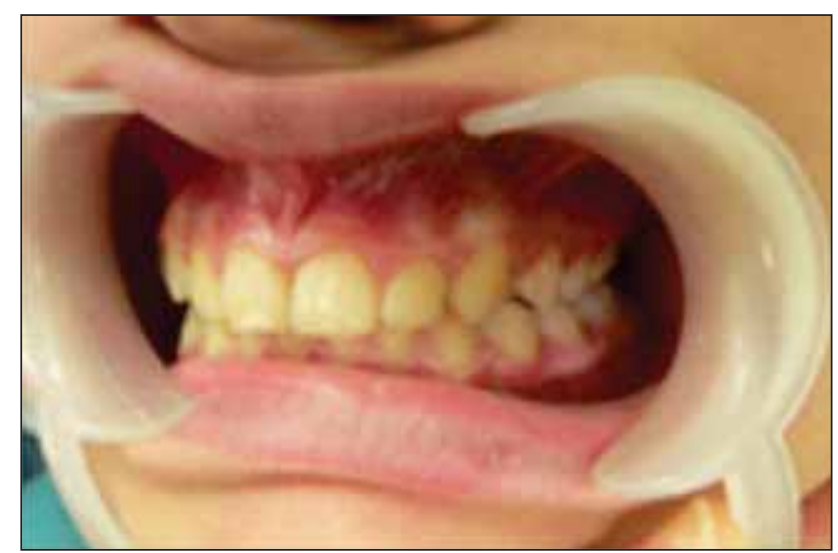

FIGURA 15. Aspect endobucal 


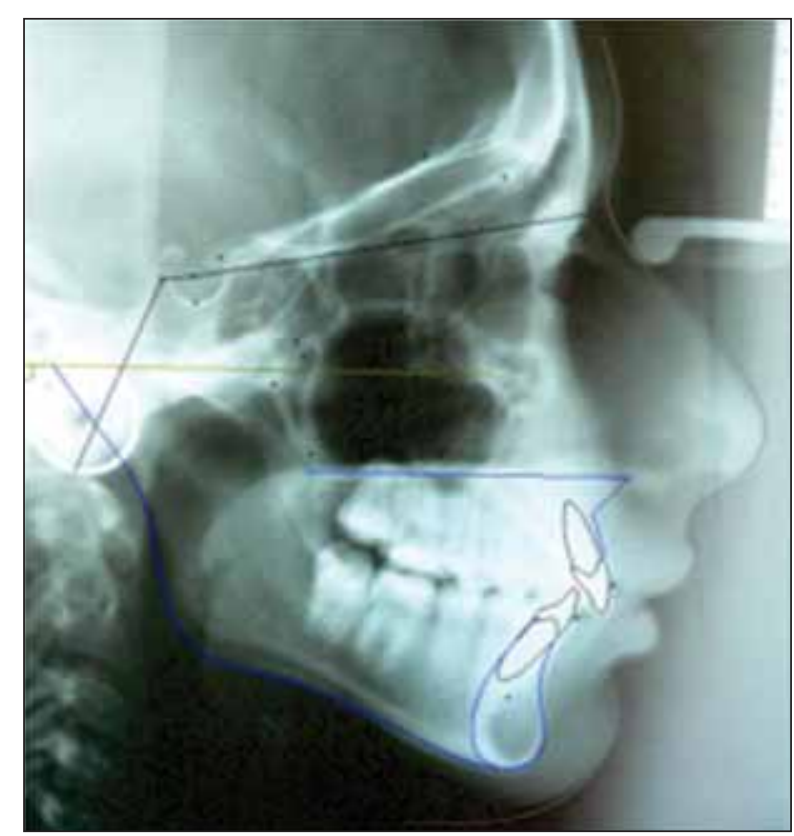

FIGURA 16. Teleradiografia de profil intermediară

S-a realizat suprapunerea teleradiografiilor de profil:

- planul Sellae-Nasion;

- planul bispinal.

Se remarcă o direcție de creştere favorabilă (Fig. 17).

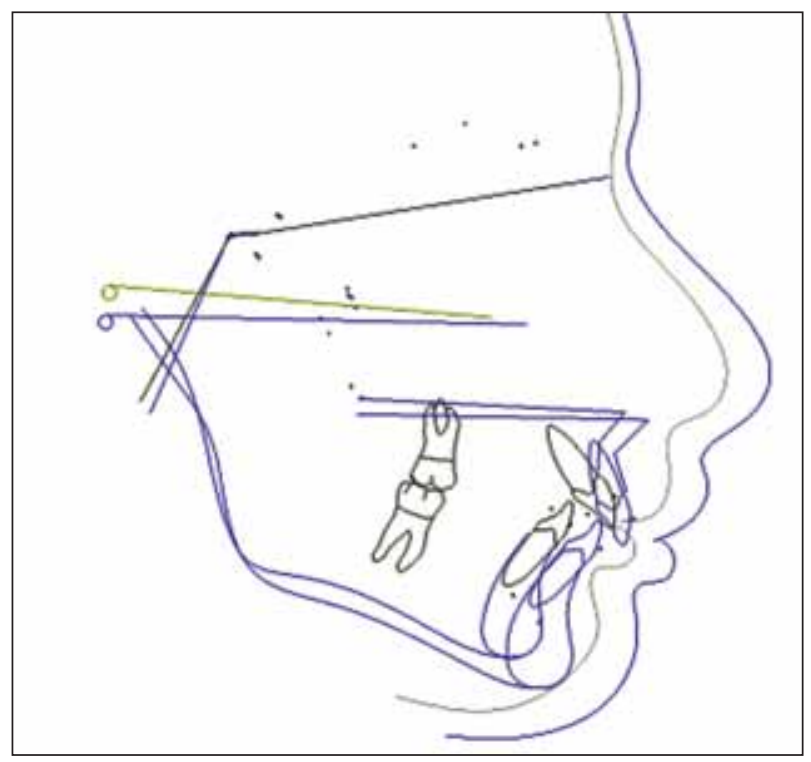

Figura 17. Suprapunerea teleradiografiilor de profil pe planul Sellae-Nazion

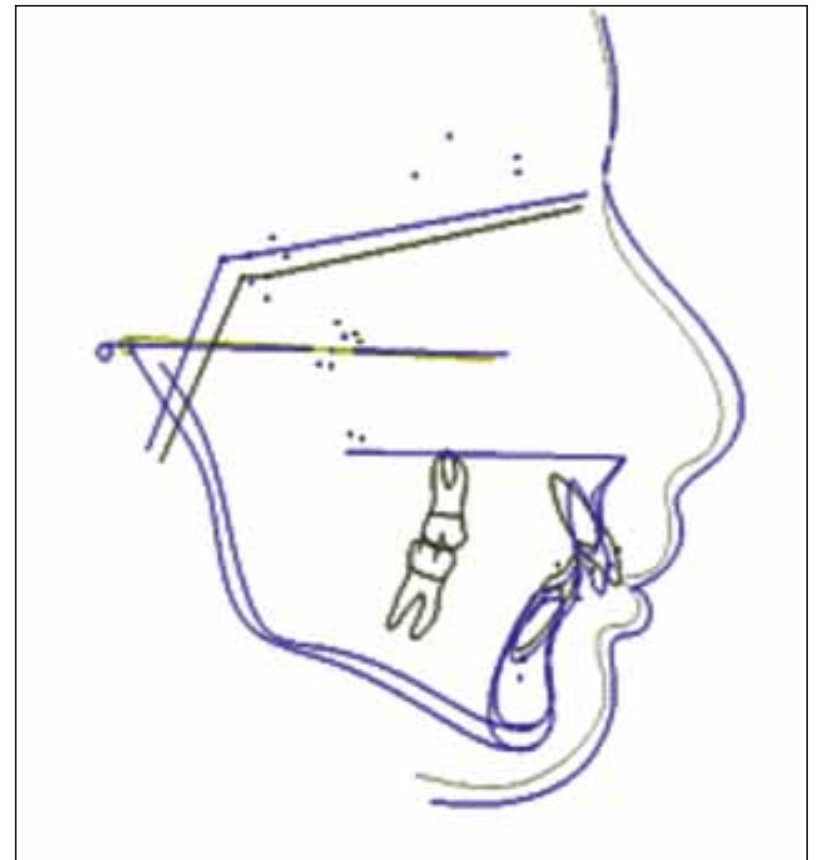

FIGURA 18. Suprapunerea teleradiografiilor de profil pe planul bispinal

TABELUL 1. Valorile analizei teleradiografiei de profil inițiale şi la 14 luni de la începerea tratamentului

\begin{tabular}{|l|c|c|}
\hline TWEED & inițial & etapa \\
\hline FMA $=25+/-3$ & 25 & 22 \\
\hline IMPA $=88+/-3$ & $94 \uparrow$ & $89^{*}$ \\
\hline SNA $=82$ & 82 & 82 \\
\hline SNB $=80$ & $74 \downarrow$ & $77^{*}$ \\
\hline ANB $=+2$ & $+8 \uparrow$ & $+5^{*}$ \\
\hline Ao-Bo & $+5 \mathrm{~mm} \uparrow$ & $+3^{*}$ \\
\hline HFA $=65 \mathrm{~mm}$ & $55 \mathrm{~mm} \downarrow$ & 64 \\
\hline HFP $=45 \mathrm{~mm}$ & $37 \mathrm{~mm} \downarrow$ & 42 \\
\hline IF $=107+/-2$ & $118 \uparrow$ & $109^{*}$ \\
\hline IM $=90$ & $94 \uparrow$ & $89^{*}$ \\
\hline$>$ Z $=78$ & $69 \downarrow$ & $76^{*}$ \\
\hline SG-PF(axaY) $=65+/-5$ & 61 & 59 \\
\hline SASSOUNI & $\begin{array}{c}\text { Cl II sch } 5 \mathrm{~mm} \\
\text { Cl II alv } 3 \mathrm{~mm} \\
\text { OB } 3 \mathrm{~mm}\end{array}$ & $\begin{array}{c}\text { Cl II sch } 4 \mathrm{~mm} \\
\text { Cl II alv } 3 \mathrm{~mm} \\
\text { OB 3 mm }\end{array}$ \\
\hline
\end{tabular}

Se remarcă reducerea treptei sagitale (Fig. 18), modificări scheletice favorabile şi ameliorarea profilului facial.

\section{CONCLUZII}

1. Frecvența anomaliilor de clasa II/1 a fost ridicată în solicitările de tratament $47 \%$

2. Tratamentul în dentația temporară şi mixtă $\mathrm{s}$-a realizat în mare majoritate a cazurilor $\mathrm{cu}$ aparate funcționale.

3. Evoluția cazurilor a fost în general favorabilă, demonstrată de modificările clinice şi ce- 
falometrice, terapia cu aparate funcționale fiind indicată în dentiția mixtă, în perioada de creştere

4. După terminarea perioadei de creştere, anomaliile de clasa II/1 necesită o reevaluare, iar finisarea se realizează cu aparate fixe. Rezul-

\section{BIBLIOGRAFIE}

1. Cocarla E. Aparate ortodontice fixe - tehnici moderne. Cluj-Napoca: Editura Medicală Universitară luliu Haţieganu, 2002

2. Proffit W.R., Fields H., Sarver D. Contemporary orthodontics. Fourth Edition, Mosby Elsevier:2007

3. Graber Th.M. , Robert L., Vanarsdall Jr. Orthodontics - Current Principles and Techniques. Third edition, Mosby: 2000

4. Ţărmure Viorica. Elemente de diagnostic şi tratament în ortodonţie. Cluj-Napoca: Editura Medicală Universitară luliu Haţieganu, 2011. tatele finale sunt mai bune la pacienții care au beneficiat de un tratament funcțional precoce.

\section{Acknowledgements}

Toți autorii au avut contribuții egale.

Conflict of interest: none declared Financial support: none declared

5. Păcurar Mariana. Aparatura ortodontică funcţională, de la clasic la modern, Tg. Mureş: Editura University Press, 2007

6. Ionescu E. Anomaliile dentare, Bucureşti: Editura Cartea Universitară, 2005

7. Ionescu E., Milicescu D.I., Popescu M., Popoviciu O., Milicescu V. Ortodonţie şi ortopedie dento-facială. Bucureşti, Ed. Cerma, 2005 